\title{
Working hours and self-rated health over 7 years: gender differences in a Korean longitudinal study
}

\author{
Seong-Sik Cho ${ }^{1,2}$, Myung Ki ${ }^{3 *}$, Keun-Hoe Kim ${ }^{4}$, Young-Su Ju${ }^{5}$, Domyung Paek ${ }^{1}$ and Wonyun Lee ${ }^{3}$
}

\begin{abstract}
Background: To investigate the association between long working hours and self-rated health (SRH), examining the roles of potential confounding and mediating factors, such as job characteristics.

Methods: Data were pooled from seven waves (2005-2011) of the Korean Labour and Income Panel Study. A total of 1578 workers who consecutively participated in all seven study years were available for analysis. A generalized estimating equation for repeated measures with binary outcome was used to examine the association between working hours (five categories; 20-35, 36-40, 41-52, 53-68 and $\geq 69$ h) and SRH (two categories; poor and good health), considering possible confounders and serial correlation.

Results: Associations between working hours and SRH were observed among women, but only for the category of the shortest working hours among men. The associations with the category of shortest working hours among men and women disappeared after adjustment for socioeconomic factors. Among women, though not men, working longer than standard hours (36-40 h) showed a linear association with poor health; OR $=1.41(95 \% \mathrm{Cl}=1.08-1.84)$ for 52-68 working hours and $\mathrm{OR}=2.11$ (95\% Cl=1.42-3.12) for $\geq 69$ working hours. This association persisted after serial adjustments. However, it was substantially attenuated with the addition of socioeconomic factors (e.g., $\mathrm{OR}=1.66(95 \% \mathrm{Cl}=1.07-2.57)$ ) but only slightly attenuated with further adjustment for behavioural factors (e.g., $\mathrm{OR}=1.63(95 \% \mathrm{Cl}=1.05-2.53)$ ). The associations with job satisfaction were significant for men and women.
\end{abstract}

Conclusions: The worsening of SRH with increasing working hours only among women suggests that female workers are more vulnerable to long working hours because of family responsibilities in addition to their workload.

Keywords: Working hours, Self-rated health, Gender

\section{Background}

South Korea (hereafter Korea) had the longest working hours between 1980 and 2007 and the second longest since 2007 after Mexico among the Organization for Economic Cooperation and Development countries [1]. In principle, legal working hours in Korea are $40 \mathrm{~h}$ per week based on a five-day working week system with the establishment of a legal limitation of working hour per week - not to exceed $52 \mathrm{~h}$. This legislation was introduced in 2004 from public sector and companies with over 1000 full-time workers and gradually extended to

\footnotetext{
*Correspondence: myungki@eulji.ac.kr

${ }^{3}$ Department of Preventive Medicine, School of Medicine, Eulji University,

143-5, Yongdu-dong, Jung-gu, Daejeon, South Korea

Full list of author information is available at the end of the article
}

companies with five full-time workers or more in 2011. Despite the five-day working policy, working long hours has still been routine culture in Korea, partly because of rising job insecurity and high work pressure.

Globally, and recently in Korea, previous studies reported, with sufficient evidence, the negative effects of long working hours on health, including depressive symptoms [2-4], sleep disturbance $[5,6]$ and cardiovascular disease [7-10], which is often best recognized by the word karoshi (death from overwork). Inconsistency in associations of long working hours has been observed for diabetes [10], health behaviour [11], obesity [12], suicide [13], and self-rated health (SRH) [14]. Much of this inconsistency may be attributable to the complexity involved in defining working hours in the 
modern working environment. With the expansion of precarious work over recent decades, the components of long working hours have become increasingly less standardized and have become a function of many factors: job insecurity, autonomy, enjoyment and self-fulfilment, high demands, work schedule, and job satisfaction [8, 15-17].

Despite the advances in elucidating the details of the nature of working hours, unanswered questions remain on the distinction between the combined and separate effects of working hours and other job characteristics. Earlier studies reported that the effects of working hours were in operation in combination with, for example, length of rest break [18] and work flexibility [17] rather than alone. Similarly, long working hours have been proposed as a predisposing factor for shift work tolerance [19]. Moreover, some recent studies have shown that some workers are forced to take part-time jobs because of the reasons for constrained competence such as health problems $[3,20]$. In line with this, when shorter working hours were concurrent with rising work intensity, it had no noticeable positive effects [21]. Such findings suggest that the benefits of short working hours may not be fully measurable in an unfavourable situation where the working environment becomes increasingly insecure and competitive like in Korea. Though variability in working hours has increased across both sides of standard working hours ( $40 \mathrm{~h}$ in Korea), to date, research on short working hours has been largely neglected. Further, there is uncertainty as to how long working hours negatively affects health. Long working hours tend to co-occur with unhealthy behaviours and could be a proxy for lower socioeconomic status $[11,22]$. Though, to some extent, prior studies included either behavioural or socioeconomic factors, it is still unclear whether long working hours have independent effects and, if not, what factors mainly account for the effects of long working hours. Lastly, it is well-known that poor health plays an active role in constructing the gender gap in paid employment and employment transition and generally plays a more significant role for women than for men [23]. This implies that women may have higher risks from long working hours, but the evidence is scarce.

Given insufficient understanding of some details, we investigated the association between working hours and SRH using a large Korean longitudinal data. This study aimed to examine whether (1) working hours (both short and long working hours) are associated with SRH, with particular attention to gender differences, (2) the associations are influenced by other domains of job characteristics such as job satisfaction and work shift, and (3) the associations are independent of socio-demographic and behavioural factors.

\section{Methods}

\section{Study population}

The Korean Labour and Income Panel Study (KLIPS) is an ongoing longitudinal survey of a nationally representative sample. The same individuals were re-interviewed each year about various social and economic activities, including employment, income, education, and training. The study subjects used here were drawn from seven waves of the KLIPS between 2005 and 2011 (from the 8 th to the 14th wave), where relevant information was available. Initially, 4086 workers who had no missing values on SRH and working hours were included. After exclusion of individuals who did not participate in all of the seven consecutive years, a total of 1578 workers remained for analysis of balanced panel data to make equal contributions from all of the participants. Ethical approval was obtained from the Institutional Research Board at Konkuk University Hospital, and secondary data analysis was performed without identifying personal information.

\section{Measures}

As a health measure, SRH over the last 12 months was used. A 5-point scale of SRH was collapsed into two categories: a rating of "very good" or "good" health status was identified as "good health" and a rating of "fair", "poor", or "very poor" health status was regarded as "poor health". For participants who worked on a regular basis, working hours were calculated by asking a set of two questions: "What are your current regular working hours for a week excluding meal times?" and "On average, how many hours do you work overtime per week?" For workers who did not work on a regular basis, working hours were assessed by asking: "How many hours do you work in a week on average?" Working hours with a minimum of at least $20 \mathrm{~h}$ were categorized into five groups to reflect the current status of working hours authorized by Korean law, and the significance for each category is indicated in parenthesis; $20-35 \mathrm{~h}$ (less than standard working hours), 36-40 h (standard working hours), 41-52 h (overtime within legally permitted working hours per week excluding weekend work), 53-68 h (overtime within legally permitted working hours per week including weekend work) and $69 \mathrm{~h}$ or more (legally prohibited working hours in any circumstances). Binary variables were generated for working days per week (i.e. $\leq 5$ days or $>5$ days), shift work and job satisfaction (i.e. yes or no). Based on the Korean Standard Industrial Classification, industrial sectors were grouped into five categories as follow; agriculture, fishing, mining and construction; manufacturing; retail, restaurant and hotel; financing, estate, transportation and information; health, social, educational and household services. Initially, occupations were classified into 10 major groups according to 
the Korean Standard Classification of Occupation and then collapsed into three categories; manager and professional (managers, professionals, technicians and associate professionals), white collar workers (clerks, service and sales workers) and manual workers (skilled agricultural and fishery workers, craftsmen and related workers, plant and machine operators and elementary occupations).

Relevant socio-demographic and behavioural covariates were identified from previous studies. Three categories of educational attainment were distinguished: middle school or less, high school, undergraduate and postgraduate. Monthly income was based on a single question about the amount of wages earned in the previous month; data were then grouped into quintiles. Employment status was grouped into three categories: regular, temporary and day labour, on the grounds of the contract period. Smoking habits were classified into two categories: current smoker vs ex- and nonsmoker. Similarly, alcohol consumption was graded into two categories: current alcohol drinkers vs exand non-drinkers.

\section{Statistical analysis}

To explore the basic characteristics of the study population and basic associations, simple descriptive statistics were reported from the data pooled over seven years. For the analyses of association between working hours and SRH, the generalized estimating equation was applied to adjust for confounders and to consider the serial correlation between repeated measures within an individual. To clarify the temporal intervals, SRH in $t+1$ year was secured to be ahead of predictors in the preceding $t$ year (a lag time of 1 year). Application of a set of covariates for adjustments was identified using the Directed Acyclic Graph (DAG) approach [24], which is able to achieve a model selection accounting for a conceptual causal relationship. When a list of variables becomes sufficient enough to minimize confounding and selection bias under a causal assumption [25], DAG presents a model described as 'minimal sufficient adjustment set' of covariates. Models were fitted with different adjustments for covariates and stratified by gender. Model 1 was fitted only for working hours. Model 2 identifying a minimally sufficient adjustment set included age, working days, monthly wage, educational level, shift work, job status, along with long working hours. Then, additional to the covariates defined in the Model 2, further adjustment was made for behavioural factors (smoking and alcohol) and job satisfaction (Model 3). We tested this model with DAG and found that it is sufficient to build a causal structure between long working hours and SRH (Additional file 1). Statistical inference applied to panel data depends on time period in use, as Individual effects change over time; that is, for example, SRH declines with ages. It is therefore argued that the time-varying nature of SRH can be better modeled by introducing a longer panel $[26,27]$. Panels have lasted for one to seven waves in the current study and, to minimize the perioddependent heterogeneity, we included only individuals who provided entire information on the variables specified in the Model 3 over all seven years (six observations per each individual, as the associations of predictors with SRH in the current study was defined to occur over a period of year $t$ to $t+1$ ). We also conducted analyses involving a different timescale with cross-sectional association (no time lag) and a similar magnitude and pattern of associations was observed (data not presented). To assess potential bias associated with the categorization, we repeated the same analysis with a slightly different definition of SRH; good ("very good", "good" or "fair") versus poor ("poor" or "very poor") health status and associations were similar (data not presented) to the results presented here. Statistical analyses were conducted with STATA ver13 (StataCorp LP, Texas, USA) and an online program "dagitty" [28] for DAG analysis.

\section{Result}

The study population comprised 6432 observations from 1072 men and 3036 observations from 506 women (Table 1). Men and women were similar in age distribution. Women had a higher proportion of poor health than men (38.9 vs $30.7 \%$ ). Approximately, $75 \%$ of men and $70 \%$ of women worked more than the standard working hours ( $40 \mathrm{~h}$ per week) but more women worked longer than 5 days per week than men. Compared to men, women were in less secure jobs, with more of them in temporary or day labour jobs, but women were less likely to do shift or night work and were more in the white collar workers category. Women were less educated and $27.2 \%$ of women and $14.0 \%$ of men did not finish high school.

Socio-demographic differences across a range of working hours were presented (Table 2). Men were more in the categories of longer working hours than women. In general, when workers were in unfavourable situations (e.g. poor health, less than university level education, and receiving a lower monthly wage), they worked longer working hours. The gap in working hours across categories of these characteristics was larger among women than men. For example, women with less than high school education who worked over 52 working hours were $39.9 \%$ and the proportion of those with university education was down to $12.7 \%$. However, the corresponding figures among men were 36.5 and $27.5 \%$, and the gap was far narrower than that of women. However, those with a better labour market position such as regular and day workers were likely to work longer hours, which was particularly apparent among men. 
Table 1 Socio-demographic characteristics of the study sample pooled over seven years (2005-2011) in the Korean Labour and Income Panel Study

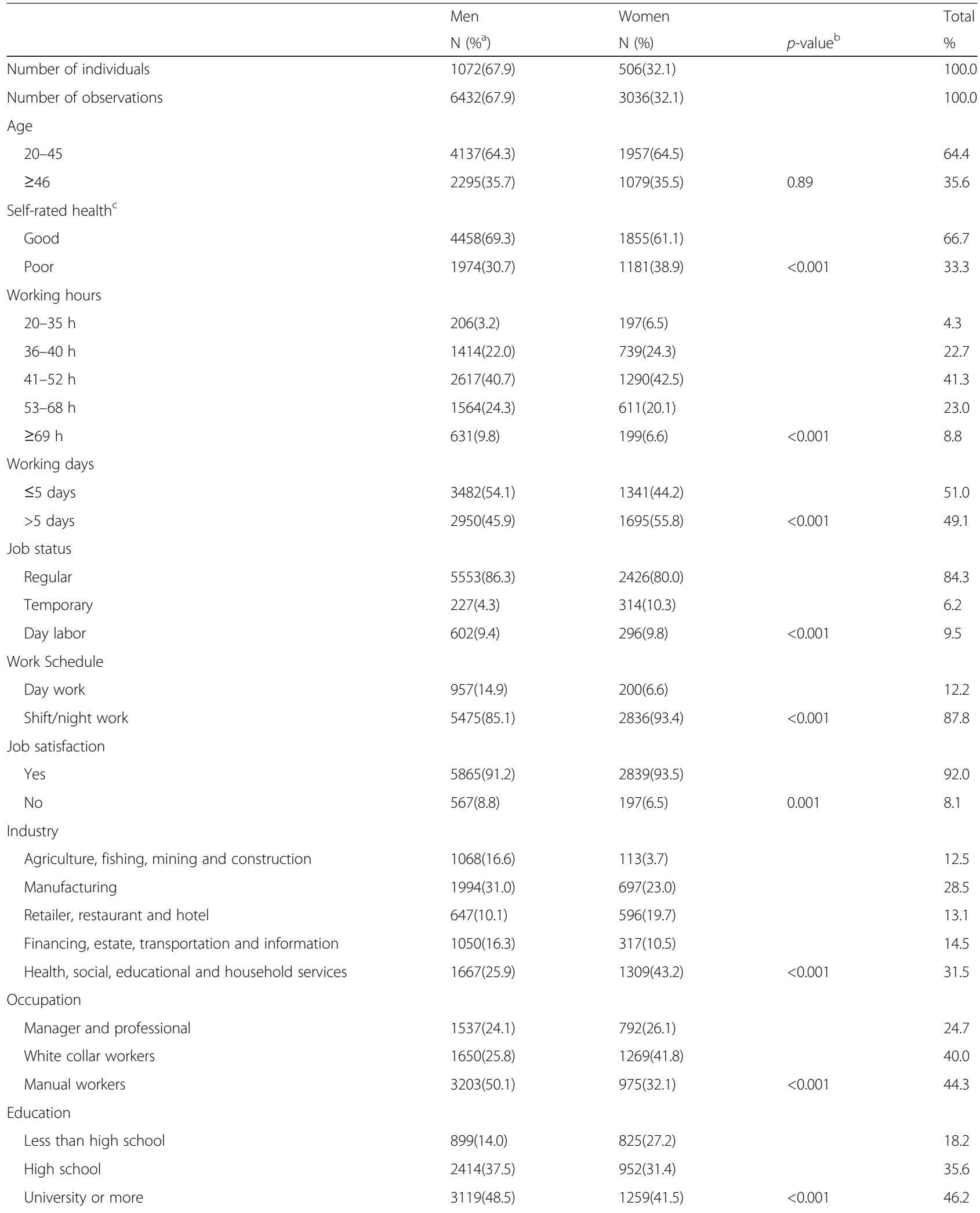


Table 1 Socio-demographic characteristics of the study sample pooled over seven years (2005-2011) in the Korean Labour and Income Panel Study (Continued)

\begin{tabular}{|c|c|c|c|c|}
\hline \multicolumn{5}{|l|}{ Monthly wage } \\
\hline 1 (lowest quintile) & $270(4.2)$ & $810(26.7)$ & & 11.4 \\
\hline 2 & $565(8.8)$ & $876(28.9)$ & & 15.2 \\
\hline 3 & 1238(19.3) & $523(17.2)$ & & 18.6 \\
\hline 4 & 1926(29.9) & $425(14.0)$ & & 24.8 \\
\hline 5 (highest quintile) & $2433(37.8)$ & $402(13.2)$ & $<0.001$ & 29.9 \\
\hline \multicolumn{5}{|l|}{ Smoking } \\
\hline Yes & $3586(55.8)$ & $35(1.2)$ & & 38.2 \\
\hline No & $2846(44.3)$ & $3001(98.9)$ & $<0.001$ & 61.8 \\
\hline \multicolumn{5}{|l|}{ Drinking } \\
\hline Yes & $5453(84.8)$ & $1624(53.5)$ & & 74.8 \\
\hline No & $979(15.2)$ & $1412(46.5)$ & $<0.001$ & 25.3 \\
\hline
\end{tabular}

a\%: row frequency apart from number of observations and individuals

${ }^{\mathrm{b}} p$-value was obtained from Chi-square test

${ }^{\mathrm{C}}$ For self-rated health, data were pooled over a period between 2006 and 2011, but for all other measures between 2005 and 2010

The bivariate relationship between predictors and SRH is shown in Table 3. The level of working hours had a U-shaped association with a higher risk of poor health. That is, in general, the highest risk of poor health occurred among those who worked the shortest hours (20-35 h), followed by those who worked the longest hours $(\geq 69 \mathrm{~h})$. The lowest risk was observed in the range of 41-52 working hours both in men and women. Workers on a regular contract were less likely to have poor health, but no significant differences were observed between categories of work schedules. The pattern of association between socioeconomic factors and poor health status showed a gradient from more to less advantaged for both education and wage, which was common in men and women. There was a higher risk of poor health with smoking, which was more pronounced among women, while the trend for drinking was in the opposite direction: i.e. those who drank more had better SRH.

In the multivariate analysis (Table 4), the association of working hours with SRH among men was only found in the shortest category of working hours $(20-35 \mathrm{~h})$ $(\mathrm{OR}=2.16,95 \% \mathrm{CI}=1.54-3.02)$ (Model 1). Similarly, among women, the shortest category of working hours was associated with a higher risk of poor health. These associations disappeared after adjustment, mainly for socioeconomic factors (Model 2). Among women, apart from the category of the shortest working hours, there was an increasing trend of risk of poor health with an increase of working hours. To illustrate, as compared to standard working hours (36-40 h), long working hours of 52-68 $\mathrm{h}$ and $\geq 69 \mathrm{~h}$ were both associated with an incremental increase of poor health, shown by ORs of 1.41 $(95 \% \mathrm{CI}=1.08-1.84)$ for the former and of 2.11 (95\%
$\mathrm{CI}=1.42-3.12$ ) for the latter (Model 1). Only the association of $\geq 69$ working hours persisted even after serial adjustments; however, it was substantially attenuated with the addition of socioeconomic factors (e.g. $\mathrm{OR}=$ 1.66 (95\% CI $=1.07-2.57$ ) for $\geq 69$ working hours) but only slightly attenuated after further adjustment for behavioural factors (e.g. $\mathrm{OR}=1.63(95 \% \mathrm{CI}=1.05-2.03)$ for $\geq 69$ working hours). Among other job characteristics, effects of day labour, as compared to a regular job, were significant and persisted across all models. No association was found for work schedule. The associations with job satisfaction were significant for men $(\mathrm{OR}=1.34$ $(95 \% \mathrm{CI}=1.11-1.63)$ ) and were borderline significant for women $(\mathrm{OR}=1.43(95 \% \mathrm{CI}=0.98-2.08))$.

\section{Discussion}

In general, long working hours were closely associated with SRH, particularly among women. There was suggestive evidence for U-shaped associations; that is, adverse effects at both ends of the categories of working hours: shortest $(20-35 \mathrm{~h})$ as well as longest $(\geq 69 \mathrm{~h})$ working hours. The associations were largely attenuated after adjustment for socioeconomic factors but slightly for behavioural factors, suggesting that the associations were partly explained by socioeconomic factors. Our findings on associations for work environment support a role for job satisfaction as a measure of the overall evaluation over one's working environment, independent of long working hours.

\section{Methodological considerations}

A major strength of this study is the use of a full range of working hours including short working hours, instead of narrowly focusing on overtime. The availability of a 
Table 2 Sample characteristics across a range of working hours by men and women pooled over seven years (2005-2011) in the Korean Labour and Income Panel Study

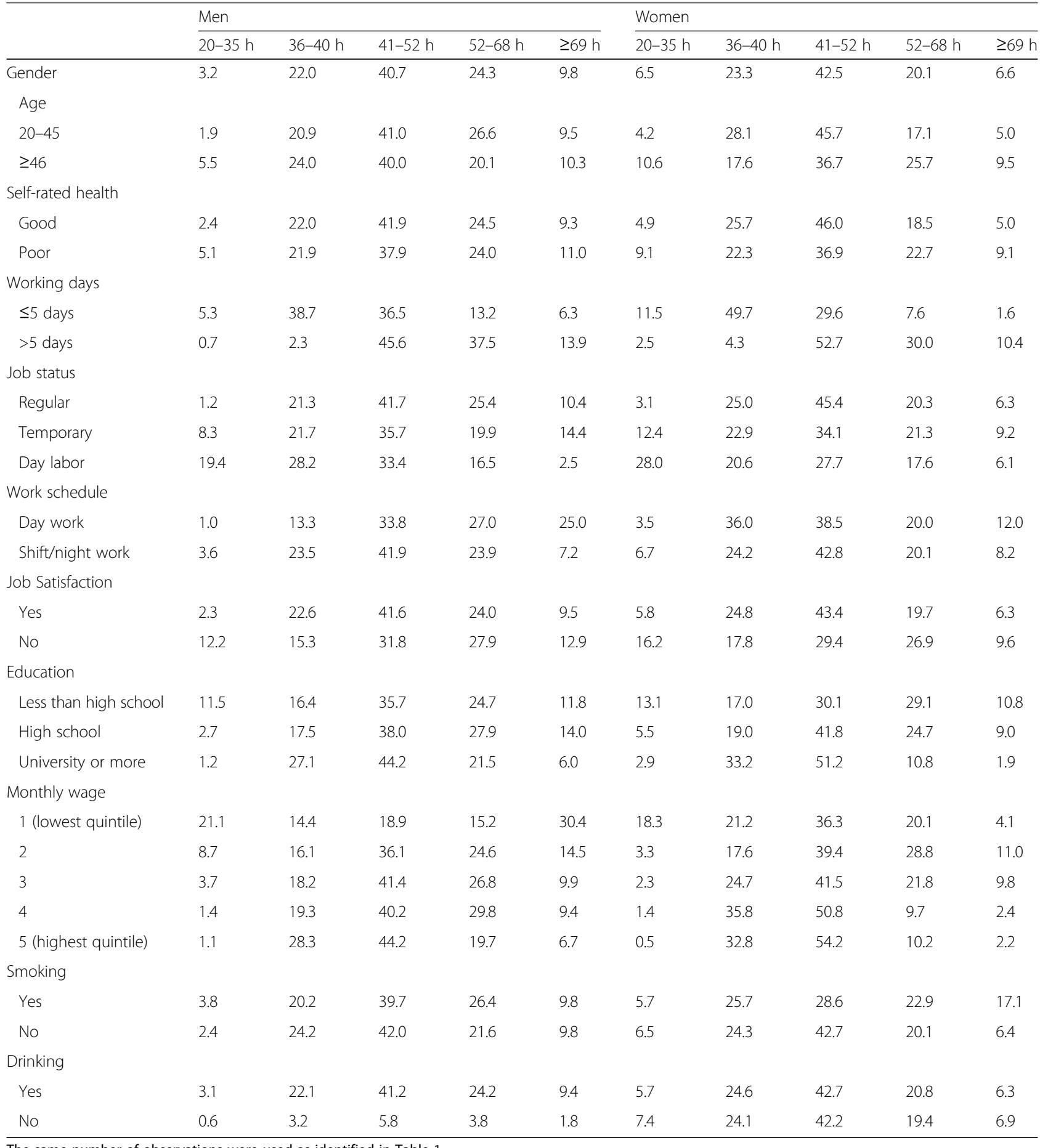

relatively wide range of covariates, including working conditions, socioeconomic and behavioural factors, was important to allow examination of certain details. By providing different sets of adjustment covariates, we were partly able to test the separate effects of the factors. Further, compared to cross-sectional data, panel data can provide better estimates by controlling for unobserved heterogeneity and offers gains in establishing causality. Study strengths include the application of DAG, which was used for model selection to identify the minimally sufficient adjustment sets. Although DAG approach is based on the deduction of causal structure 
Table 3 Bivariate associations of working hours and other measures with self-rated health by men and women pooled over seven years (2005-2011) in the Korean Labour and Income Panel Study

\begin{tabular}{|c|c|c|c|c|c|c|}
\hline & \multicolumn{3}{|l|}{ Men } & \multicolumn{3}{|l|}{ Women } \\
\hline & Good health & Poor health & $P$-value ${ }^{a}$ & Good health & Poor health & $P$-value \\
\hline \multicolumn{7}{|l|}{ Age } \\
\hline $20-45$ & 73.7 & 26.3 & & 71.0 & 29.0 & \\
\hline$\geq 46$ & 61.4 & 38.7 & $<0.001$ & 43.2 & 56.8 & $<0.001$ \\
\hline \multicolumn{7}{|l|}{ Working hours } \\
\hline $20-35 \mathrm{~h}$ & 51.0 & 49.0 & & 45.7 & 54.3 & \\
\hline $36-40 \mathrm{~h}$ & 69.4 & 30.6 & & 64.4 & 35.6 & \\
\hline $41-52 \mathrm{~h}$ & 71.4 & 28.6 & & 66.2 & 33.8 & \\
\hline $53-68 \mathrm{~h}$ & 69.7 & 30.3 & & 56.1 & 43.9 & \\
\hline$\geq 69 \mathrm{~h}$ & 65.6 & 34.4 & $<0.001$ & 46.2 & 53.8 & $<0.001$ \\
\hline \multicolumn{7}{|l|}{ Work day } \\
\hline$\leq 5$ days & 69.6 & 30.4 & & 61.9 & 38.1 & \\
\hline$>5$ days & 69.0 & 31.1 & 0.56 & 60.5 & 39.5 & 0.42 \\
\hline \multicolumn{7}{|l|}{ Job status } \\
\hline Regular & 71.6 & 28.4 & & 65.9 & 34.1 & \\
\hline Temporary & 64.3 & 35.7 & & 48.1 & 51.9 & \\
\hline Day labor & 50.5 & 49.5 & $<0.001$ & 35.8 & 64.2 & $<0.001$ \\
\hline \multicolumn{7}{|l|}{ Work Schedule } \\
\hline Day work & 67.4 & 32.6 & & 51.0 & 49.0 & \\
\hline Shift/night work & 69.6 & 30.4 & 0.16 & 61.8 & 38.2 & 0.002 \\
\hline \multicolumn{7}{|l|}{ Job satisfaction } \\
\hline Yes & 70.6 & 29.4 & & & & \\
\hline No & 56.3 & 43.7 & $<0.001$ & & & $<0.001$ \\
\hline \multicolumn{7}{|l|}{ Education } \\
\hline Less than high school & 52.5 & 47.5 & & 37.2 & 62.8 & \\
\hline High school & 67.9 & 32.1 & & 62.7 & 37.3 & \\
\hline University or more & 75.3 & 24.8 & $<0.001$ & 75.5 & 24.5 & $<0.001$ \\
\hline \multicolumn{7}{|l|}{ Monthly wage } \\
\hline 1 (lowest quintile) & 50.0 & 50.0 & & 44.3 & 55.7 & \\
\hline 2 & 58.2 & 41.8 & & 27.9 & 30.3 & \\
\hline 3 & 66.3 & 33.7 & & 68.8 & 31.2 & \\
\hline 4 & 69.5 & 30.5 & & 77.2 & 22.8 & \\
\hline 5 (highest quintile) & 75.4 & 24.6 & $<0.001$ & 72.1 & 27.9 & $<0.001$ \\
\hline \multicolumn{7}{|l|}{ Smoking } \\
\hline Yes & 67.9 & 32.1 & & 37.1 & 62.9 & \\
\hline No & 45.4 & 41.7 & 0.006 & 61.4 & 38.6 & 0.004 \\
\hline \multicolumn{7}{|l|}{ Drinking } \\
\hline Yes & 69.8 & 30.2 & & 55.3 & 49.1 & \\
\hline No & 66.4 & 33.6 & 0.03 & 43.7 & 50.9 & $<0.001$ \\
\hline
\end{tabular}

The same number of observations were used as identified in Table 1

${ }^{a} p$-value was obtained from Chi-square test 
Table 4 Multivariate associations of working hours and other work characteristics with poor self-rated health by men and women pooled over seven years (2005-2011) in the Korean Labour and Income Panel Study

\begin{tabular}{|c|c|c|c|c|c|c|}
\hline & \multicolumn{3}{|l|}{ Men } & \multicolumn{3}{|l|}{ Women } \\
\hline & Model $1^{\mathrm{a}}$ & Model $2^{b}$ & Model $3^{c}$ & Model 1 & Model 2 & Model 3 \\
\hline & OR $(95 \% \mathrm{Cl})^{d}$ & OR $(95 \%$ Cl) & OR (95\% Cl) & OR (95\% Cl) & OR (95 \% Cl) & OR (95 \% Cl) \\
\hline \multicolumn{7}{|l|}{ Working hours } \\
\hline $20-35$ h & $2.16(1.54,3.02)$ & $1.11(0.80,1.54)$ & $1.06(0.76,1.48)$ & $2.15(1.44,3.22)$ & $0.97(0.65,1.44)$ & $0.96(0.65,1.43)$ \\
\hline $36-40 \mathrm{~h}$ & Reference ${ }^{e}$ & Reference & Reference & Reference & Reference & Reference \\
\hline $41-52 \mathrm{~h}$ & $0.91(0.77,1.07)$ & $0.89(0.75,1.07)$ & $0.89(0.75,1.07)$ & $0.92(0.73,1.16)$ & $1.00(0.76,1.30)$ & $1.00(0.77,1.31)$ \\
\hline $52-68 \mathrm{~h}$ & $0.98(0.82,1.18)$ & $0.94(0.77,1.16)$ & $0.93(0.75,1.14)$ & $1.41(1.08,1.84)$ & $1.16(0.85,1.60)$ & $1.17(0.85,1.60)$ \\
\hline$\geq 69 \mathrm{~h}$ & $1.18(0.92,1.50)$ & $1.03(0.79,1.33)$ & $1.02(0.78,1.31)$ & $2.11(1.42,3.12)$ & $1.66(1.07,2.57)$ & $1.63(1.05,2.53)$ \\
\hline \multicolumn{7}{|l|}{ Working days } \\
\hline$\leq 5$ & & Reference & Reference & & Reference & Reference \\
\hline$>5$ & & $1.03(0.88,1.21)$ & $1.03(0.88,1.20)$ & & $0.81(0.64,1.04)$ & \\
\hline \multicolumn{7}{|l|}{ Job status } \\
\hline Regular & & Reference & Reference & & Reference & Reference \\
\hline Temporary & & $0.91(0.65,1.27)$ & $0.89(0.63,1.24)$ & & $1.37(0.98,1.93)$ & $1.35(0.96,1.89)$ \\
\hline Day labour & & $1.62(1.25,2.11)$ & $1.54(1.18,2.00)$ & & $1.45(0.98,2.15)$ & $1.42(0.96,2.10)$ \\
\hline \multicolumn{7}{|l|}{ Work schedule } \\
\hline Day work & & Reference & Reference & & Reference & Reference \\
\hline Shift/night work & & $1.04(0.85,1.27)$ & $1.05(0.86,1.28)$ & & $1.64(1.12,2.38)$ & $1.64(1.13,2.39)$ \\
\hline \multicolumn{7}{|l|}{ Job satisfaction } \\
\hline Yes & & & Reference & & & Reference \\
\hline No & & & $1.34(1.11,1.63)$ & & & $1.43(0.98,2.08)$ \\
\hline
\end{tabular}

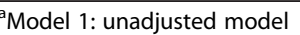

${ }^{\mathrm{b}}$ Model 2: adjusted for age, income and education as well as covariates listed in Table 3

cModel 3: adjusted for smoking, alcohol consumption and job satisfaction additional covariates in Model 2

${ }^{d}$ Association was estimated using generalized estimation equation

${ }^{\mathrm{e}}$ Reference indicates a reference category

among variables under investigation, it is supposed to reduce the degree of confounding and selection bias by better representing the underlying causal relationship [25]. There were some potential limitations to our study. SRH may be too broad to detect specific influences of working hours on health. However, SRH is strongly correlated with objective health status [29] and is used as a relevant single measure, particularly when various health influences are expected to include both physical and mental aspects [30]. Though sample restriction to workers who stayed in employment over all of the 6 study years was motivated by the preference to balanced data over unbalanced data, this might result in 'the healthy worker survival effect'. In a sensitivity analysis, comparing between those who stayed in the sample and those who did not, a lower proportion of poor self-rated health, longer working hours, more frequent regular job, and higher amount of wage were favourable among the former (data not presented). Selective loss of unhealthy workers consequently may have contributed to underestimates of the adverse impact of long working hours on SRH. Another limitation concerns unmeasured confounding factors such as sleep hours and occupational stress, which could not be assessed due to a lack of available data.

\section{Interpretation and comparisons with previous studies}

Consistent with some previous studies but not all, we found a negative association between long working hours and SRH. The ways through which long working hours affect workers' health status are yet to be explored. Most obviously, long working hours were closely linked with work demands, thereby leading to an increase of occupational stress and bringing on poor general health. Other explanations include extended exposure to hazardous physical, chemical and psychological factors, and insufficient recovery due to short sleep duration [31]. Whether socioeconomic and behavioural factors modify the association between working hours and health is an important issue, and this study, with serial adjustments across models, showed substantial effects of socioeconomic factors but negligible effects of behavioural factors. This may seem to be inconsistent with the argument that long working hours disrupt 
health behaviours, which in turn partly mediate the relationship between working hours and health [31, 32]. However, this finding echoes previous studies [33], in which work environment explained a larger portion of socioeconomic differences in SRH than did behavioural factors. This implies that those exposed to both long and short working hours may co-exist with other adverse risks, which are more common to those of lower socioeconomic status. Another explanation may be provided from a data construction point of view; among workers who maintained paid employment for long years as seen in our sample, the adverse effects of long working hours through the behavioural path may be minimized for adaptation. This suggests that enabling people to stay in employment may help to promote healthy behaviours, which may be particularly prominent among women.

The worsening of SRH with increasing working hours was found only among women. This finding agrees with previous studies $[2,3,34]$, including a study from the same population [35], which was limited to a crosssectional analysis from one wave of the KLIPS. Two hypotheses can be addressed for explanation. First, female workers may be under the 'double burden': family and work responsibilities [36]. Though the hypothesis was not tested in the current study, in a study from Korea, female workers took most of the household tasks after work time [37]; women thereby became more susceptible to experiencing health problems. Second, this observation may be rooted in the unequal power relation between men and women, which consequently is reflected in the labour market position. Women often worked in more precarious and subordinate positions than men, as broadly shown in the current study (Tables 1 and 2) and other studies [38]. This subsequently leads to more exposure to hazardous and unfavourable working conditions towards women's health [39]. However, the gender difference may also be because of the health measure used in this study; that is SRH. Women tend to report poorer SRH than men across countries and age groups [40], though the evidence on whether women's assessment of their own health relative to their actual health status is more negative than men is unclear [41, 42]. Putting things together, long working hours may have a greater negative impact on women than men under the same conditions.

Interestingly, our study suggests that both the shortest as well as the longest working hours are associated with poorer SRH, resulting in a U-shaped association. This pattern, though not conclusive, was similarly observed in a meta-analysis for coronary heart disease [43], while other studies reported a gradual increase of poor health in response to an increase of working hours [44, 45], where working hours shorter than a standard category was mostly neglected. Reverse causation may be plausible. Despite the longitudinal nature of this study, poor health might affect the ability to work [23], as participants were not free from poor health at baseline. Thus, some of those who work short hours do physically light work because of health reasons, though such findings remain to be explored. This, together with another finding that the association was markedly attenuated by further adjustment for socioeconomic factors, implies that there has been bi-directional accumulation between poor health and lower socioeconomic status; those who work short hours do so as more of their socio-economical vulnerability than as of voluntary choice [46]. More attention in future studies needs to be paid to cover a wider range of working hours as the atypical nature of working hours is increasing at both ends of the range. A potential independent association of job satisfaction is also important. Job satisfaction represents the subjective combination of job security, control over workload, and levels of enjoyment [47]. Since the concept relates to a general condition rather than domain specific, job satisfaction is expected to be of potential importance for workplace policies aimed at improving employee's global health status.

\section{Conclusion}

Long working hours were associated with a higher level of poor health. The impact was larger among female workers, who frequently continue to manage the demand of double role in family and work. The health risk of long working hours was partly explained by socioeconomic condition. In sum, this study addresses that the reduction in working hours could be a better measure for labour protection, when coupled with improvements in other adversities tied to gender and socioeconomic status (i.e., traditional gender role and precarious job characteristics).

\section{Additional file}

Additional file 1: Directed acyclic graph illustrating the hypothesized pathway of working hours to self-rated health and associated covariates. (PDF $81 \mathrm{~kb}$ )

\section{Abbreviations \\ Cl: Confidence interval; DAG: Directed Acyclic Graph; KLIPS: The Korean Labour and Income Panel Study; OR: Odds ratio; SRH: Self-rated Health.}

Competing interests

The authors declare that they have no competing interests.

Authors' contributions

SSC and MK conceived and designed this study. SSC, MK and KHK were involved in data acquisition and analysis. SSC and MK interpreted the results and wrote the first draft and SSC, MK, KHK, YSJ, DMP, and WYL were involved in revision of the subsequent drafts. All authors read and approved the final manuscript. 


\section{Acknowledgements}

This research was partly supported by the Basic Science Program through the National Research Foundation of Korea (NRF) funded by the Ministry of Education (grant number: 2015014308) awarded to MK.

\section{Author details}

'Department of Occupational and Environmental Health, Graduate School of Public Health, Seoul National University, 1 Gwanak-roGwanak-gu, Seoul, South Korea. ${ }^{2}$ Department of Occupational and Environmental Medicine, Konkuk University Chungju Hospital, 82 Gukweondae-ro Chungju, Chungbuk, South Korea. ${ }^{3}$ Department of Preventive Medicine, School of Medicine, Eulji University, 143-5, Yongdu-dong, Jung-gu, Daejeon, South Korea. ${ }^{4}$ Department of Occupational and Environmental Medicine, Cheongju Medical Center, 48 Heungdeok-ro, Seowon-gu, Cheongju city, Chungbuk, South Korea. ${ }^{5}$ Department of Occupational and Environmental Medicine, Hallym University Sacred Heart Hospital, 22 Gwanpyeong-ro 170 beon-gil, Dongan-gu, Anyang, Kyeonggi, South Korea.

\section{Received: 22 August 2015 Accepted: 17 December 2015}

\section{Published online: 23 December 2015}

\section{References}

1. OECD. Average annual working time 2013/1. 2013. www.oecd-ilibrary.org/ employment/average-annual-working-time-2013-1_annual-work-table-20131-en Accessed 21 Dec 2015.

2. Kim I, Kim H, Lim S, Lee M, Bahk J, June K, et al. Working hours and depressive symptomatology among full-time employees: Results from the fourth Korean National Health and Nutrition Examination Survey (20072009). Scand J Work Environ Health. 2013;39(5):515-20.

3. Virtanen M, Ferrie JE, Singh-Manoux A, Shipley MJ, Stansfeld SA, Marmot MG, et al. Long working hours and symptoms of anxiety and depression: a 5-year follow-up of the Whitehall II study. Psychol Med. 2011;41(12):2485-94.

4. Driesen K, Jansen NW, Kant I, Mohren DC, van Amelsvoort LG. Depressed mood in the working population: associations with work schedules and working hours. Chronobiol Int. 2010;27(5):1062-79.

5. Virtanen M, Ferrie JE, Gimeno D, Vahtera J, Elovainio M, Singh-Manoux A, et al. Long working hours and sleep disturbances: the Whitehall II prospective cohort study. Sleep. 2009;32(6):737-45.

6. Sekine M, Chandola T, Martikainen P, Marmot M, Kagamimori S. Work and family characteristics as determinants of socioeconomic and sex inequalities in sleep: the Japanese civil servants study. Sleep. 2006;29(2):206-16.

7. Virtanen M, Heikkila K, Jokela M, Ferrie JE, Batty GD, Vahtera J, et al. Long working hours and coronary heart disease: a systematic review and meta-analysis. Am J Epidemiol. 2012;176(7):586-96.

8. Virtanen M, Ferrie JE, Singh-Manoux A, Shipley MJ, Vahtera J, Marmot MG, et al. Overtime work and incident coronary heart disease: the Whitehall II prospective cohort study. Eur Heart J. 2010;31(14):1737-44.

9. Jeong I, Rhie J, Kim I, Ryu I, Jung PK, Park YS, et al. Working hours and cardiovascular disease in Korean workers: a case-control study. J Occup Health. 2014;55(5):385-91.

10. Bannai A, Tamakoshi A. The association between long working hours and health: a systematic review of epidemiological evidence. Scand J Work Environ Health. 2014;40(1):5-18.

11. Artazcoz L, Cortes I, Escriba-Aguir V, Cascant L, Villegas R. Understanding the relationship of long working hours with health status and health-related behaviours. J Epidemiol Community Health. 2009;63(7):521-7.

12. Jang TW, Kim HR, Lee HE, Myong JP, Koo JW. Long work hours and obesity in Korean adult workers. J Occup Health. 2014;55(5):359-66.

13. Takeuchi A, Sakano N, Miyatake N. Combined effects of working hours, income, and leisure time on suicide in all 47 prefectures of Japan. Ind Health. 2014;52(2):137-40.

14. Bauer GF, Huber CA, Jenny GJ, Muller F, Hammig O. Socioeconomic status, working conditions and self-rated health in Switzerland: explaining the gradient in men and women. Int J Public Health. 2009;54(1):23-30.

15. Van Der Hulst M, Geurts S. Associations between overtime and psychological health in high and low reward jobs. Work Stress. 2001;15(3):227-40.

16. Hino A, Inoue A, Kawakami N, Tsuno K, Tomioka K, Nakanishi M, et al. Buffering effects of job resources on the association of overtime work hours with psychological distress in Japanese white-collar workers. Int Arch Occup Environ Health. 2015;88(5):631-40.
17. Costa G, Akerstedt T, Nachreiner F, Baltieri F, Carvalhais J, Folkard S, et al. Flexible working hours, health, and well-being in Europe: some considerations from a SALTSA project. Chronobiol Int. 2004;21(6):831-44.

18. Tucker P, Folkard S, Macdonald I. Rest breaks and accident risk. Lancet. 2003;361(9358):680.

19. Costa G. Shift work and health: current problems and preventive actions. Saf Health Work. 2010;1(2):112-23.

20. Fukuoka Y, Takeshima M, Ishii N, Chikako M, Makaya M, Groah L, et al. An initial analysis: working hours and delay in seeking care during acute coronary events. Am J Emerg Med. 2010;28(6):734-40.

21. Rudolf R. Work Shorter, Be Happier? Longitudinal Evidence from the Korean Five-Day Working Policy. J Happiness Stud. 2014;15(5):1139-63.

22. Kivimaki M, Virtanen M, Kawachi I, Nyberg ST, Alfredsson L, Batty GD, et al. Long working hours, socioeconomic status, and the risk of incident type 2 diabetes: a meta-analysis of published and unpublished data from 222120 individuals. Lancet Diabetes Endocrinol. 2015;3(1):27-34.

23. Ki M, Kelly Y, Sacker A, Nazroo J. Poor health, employment transitions and gender: evidence from the British Household Panel Survey. Int J Public Health. 2013;58(4):537-46.

24. Foraita R, Spallek J, Zeeb H. Directed Acyclic Graphs. In: Ahrens W, Pigeot I, editors. Handbook of Epidemiology. 2nd ed. New York: Springer; 2014. p. 1481-518.

25. Shrier I, Platt RW. Reducing bias through directed acyclic graphs. BMC Med Res Methodol. 2008:8:70

26. Ahn SC, Lee YH, Schmidt P. Panel data models with multiple time-varying individual effects. J Econometrics. 2013;174(1):1-14.

27. Stowasser T, Heiss F, McFadden D, Winter J. Healthy, Wealthy and Wise? Revisited: An Analysis of the Causal Pathways from Socioeconomic Status to Health. Investigations in the Economics of Aging. University of Chicago Press; 2011. p. 267-317.

28. Textor J. Drawing and analyzing causal DAGs with DAGitty: User manual for version 2.0. 2013. http://www.dagitty.net/manual-2.x.pdf. Accessed 15 Jul 2015.

29. Rutledge T, Linke SE, Johnson BD, Bittner V, Krantz DS, Whittaker KS, et al. Self-rated versus objective health indicators as predictors of major cardiovascular events: the NHLBI-sponsored Women's Ischemia Syndrome Evaluation. Psychosom Med. 2010;72(6):549-55.

30. Blaxter M. Health: Key Concepts. 2nd ed. Cambridge: Polity Press; 2010. p. 56-8.

31. Van der Hulst M. Long workhours and health. Scand J Work Environ Health. 2003;29(3):171-88.

32. Härmä M. Work hours in relation to work stress, recovery and health. Scand J Work Environ Health. 2006;32(6):502-14.

33. Borg V, Kristensen TS. Social class and self-rated health: can the gradient be explained by differences in life style or work environment? Soc Sci Med. 2000;51(7):1019-30.

34. Wirtz A, Lombardi DA, Willetts JL, Folkard S, Christiani DC. Gender differences in the effect of weekly working hours on occupational injury risk in the United States working population. Scand J Work Environ Health. 2012;38(4):349-57.

35. Song JT, Lee G, Kwon J, Park JW, Choi H, Lim S. The association between long working hours and self-rated health. Ann Occup Environ Med. 2014;26(1):2.

36. Nemoto K. Long working hours and the corporate gender divide in Japan. Gend Work Organ. 2013;20(5):512-27.

37. Kim H-K. Analyzing the gender division of labor: the cases of the United States and South Korea. Asian Perspect. 2009;33(2):181-229.

38. Campos-Serna J, Ronda-Perez E, Artazcoz L, Moen BE, Benavides FG. Gender inequalities in occupational health related to the unequal distribution of working and employment conditions: a systematic review. Int J Equity Health. 2013;12:57.

39. Matthews S, Power C. Socio-economic gradients in psychological distress: a focus on women, social roles and work-home characteristics. Soc Sci Med. 2002;54(5):799-810.

40. Hosseinpoor AR, Stewart Williams J, Amin A, Araujo De Carvalho I, Beard J, Boerma T, et al. Social determinants of self-reported health in women and men: understanding the role of gender in population health. PLoS One. 2012;7(4):e34799.

41. Voderholzer U, Al-Shajlawi A, Weske G, Feige B, Riemann D. Are there gender differences in objective and subjective sleep measures? A study of insomniacs and healthy controls. Depress Anxiety. 2003;17(3):162-72.

42. Radley A, Grove A, Wright S, Thurston H. Gender-role identity after heart attack: Links with sex and subjective health status. Psychol Health. 2000; 15(1):123-33. 
43. Kivimaki M, Jokela M, Nyberg ST, Singh-Manoux A, Fransson El, Alfredsson L, et al. Long working hours and risk of coronary heart disease and stroke: a systematic review and meta-analysis of published and unpublished data for 603838 individuals. Lancet. 2015;386(10005):1739-46.

44. Kleppa E, Sanne B, Tell GS. Working overtime is associated with anxiety and depression: the Hordaland Health Study. J Occup Environ Med. 2008:50(6):658-66.

45. Dembe AE, Erickson JB, Delbos RG, Banks SM. The impact of overtime and long work hours on occupational injuries and illnesses: new evidence from the United States. Occup Environ Med. 2005;62(9):588-97.

46. Leppel K, Clain SH. Determinants of voluntary and involuntary part-time employment. Eastern Econ J. 1993;19(1):59-70.

47. Faragher $\mathrm{EB}$, Cass $\mathrm{M}$, Cooper $\mathrm{CL}$. The relationship between job satisfaction and health: a meta-analysis. Occup Environ Med. 2005;62(2):105-12.

Submit your next manuscript to BioMed Central and we will help you at every step:

- We accept pre-submission inquiries

- Our selector tool helps you to find the most relevant journal

- We provide round the clock customer support

- Convenient online submission

- Thorough peer review

- Inclusion in PubMed and all major indexing services

- Maximum visibility for your research

Submit your manuscript at www.biomedcentral.com/submit
Biomed Central 